\title{
Impact of particle aggregation on vertical fluxes of organic matter
}

\author{
G. Karakaş ${ }^{\mathrm{a}}$, N. Nowald ${ }^{\mathrm{b}}$, C. Schäfer-Neth ${ }^{\mathrm{a}}$, M. Iversen ${ }^{\mathrm{a}}$, W. Barkmann ${ }^{\mathrm{c}}$, G. Fischer $^{\mathrm{b}}$, \\ P. Marchesiello ${ }^{\mathrm{d}}$, R. Schlitzer ${ }^{\mathrm{a}, *}$ \\ ${ }^{a}$ Alfred-Wegener-Institute for Polar and Marine Research, Am Alten Hafen 26, 27568 Bremerhaven, Germany \\ ${ }^{\mathrm{b}}$ Faculty of Geosciences and MARUM, University of Bremen, Klagenfurter and Leobener Strasse, 28359 Bremen, Germany \\ ${ }^{\mathrm{c}}$ Marine Chemistry, FB2, University of Bremen, 28334 Bremen, Germany \\ ${ }^{\mathrm{d}}$ Institut de Recherce pour le Développement Noumea Center, BP A5 Noumea Cedex, New Caledonia
}

\section{A R T I C L E I N F O}

\section{Article history:}

Received 20 July 2008

Received in revised form 23 February 2009

Accepted 16 July 2009

Available online 21 August 2009

\begin{abstract}
A B S T R A C T
Particles sinking out of the euphotic zone are important vehicles of carbon export from the surface ocean. Most of the particles produce heavier aggregates by coagulating with each other before they sink. We implemented an aggregation model into the biogeochemical model of Regional Oceanic Modelling System (ROMS) to simulate the distribution of particles in the water column and their downward transport in the Northwest African upwelling region. Accompanying settling chamber, sediment trap and particle camera measurements provide data for model validation. In situ aggregate settling velocities measured by the settling chamber were around $55 \mathrm{~m} \mathrm{~d}^{-1}$. Aggregate sizes recorded by the particle camera hardly exceeded $1 \mathrm{~mm}$. The model is based on a continuous size spectrum of aggregates, characterised by the prognostic aggregate mass and aggregate number concentration. Phytoplankton and detritus make up the aggregation pool, which has an averaged, prognostic and size dependent sinking. Model experiments were performed with dense and porous approximations of aggregates with varying maximum aggregate size and stickiness as well as with the inclusion of a disaggregation term. Similar surface productivity in all experiments has been generated in order to find the best combination of parameters that produce measured deep water fluxes. Although the experiments failed to represent surface particle number spectra, in the deep water some of them gave very similar slope and spectrum range as the particle camera observations. Particle fluxes at the mesotrophic sediment trap site off Cape Blanc (CB) have been successfully reproduced by the porous experiment with disaggregation term when particle remineralisation rate was $0.2 \mathrm{~d}^{-1}$. The aggregation-disaggregation model improves the prediction capability of the original biogeochemical model significantly by giving much better estimates of fluxes for both upper and lower trap. The results also point to the need for more studies to enhance our knowledge on particle decay and its variation and to the role that stickiness play in the distribution of vertical fluxes.
\end{abstract}

(ㄷ) 2009 Elsevier Ltd. All rights reserved.

\section{Introduction}

Particle fluxes from the ocean's surface layers to its bottom are important means of carbon export and therefore have a crucial role in the global regulation of atmospheric $\mathrm{CO}_{2}$. Many particles sinking into deep layers do so in the form of aggregates, which are produced by the coagulation of smaller particles. Coagulation does not only enhance the removal of material from euphotic zone, but it can also control the maximum phytoplankton concentration in the ocean (Jackson and Kiørboe, 2008). Among eastern boundary upwelling systems, the NW African Upwelling retains elevated concentrations of aggregates due to high biological productivity, is distinguished by their enhanced export and belongs to the most productive ecosystems of the world's ocean.

\footnotetext{
* Corresponding author. Tel.: +49 (0) 4714831 1367; fax: +49 (0) 47148311923

E-mail addresses: Gokay.Karakas@awi.de (G. Karakaş), Reiner.Schlitzer@awi.de (R. Schlitzer).
}

The efficiency of aggregate formation is regulated by factors like particle concentration, stickiness and collision rate. Although settling rates generally increase with aggregate size (Alldredge and Gotschalk, 1988, 1989), large size does not always guarantee fast sinking (Kiørboe et al., 1998) and sinking characteristics of aggregates depend on their composition, shape and porosity. The processes that can reduce the aggregate size are remineralisation, zooplankton feeding (Stemmann et al., 2004), fragmentation by zooplankton (Dilling and Alldredge, 2000) and disaggregation due to physical shear, which is caused by turbulence. The processes that aggregates go through during their sedimentation determine their vertical flux and distribution of elements they carry in the water column.

A number of models have been developed for a numerical definition of aggregation processes in the ocean with different levels of complexity. According to how collision between particles is described, Jackson (2005) classifies these models into two groups as 
those having rectilinear and curvilinear coagulation kernels. Rectilinear approximation belongs to the early formulations of coagulation, which assume that particles do not influence water motion and that chemical attraction and repulsion between particles can be ignored. Curvilinear kernels, on the contrary, take into account the effect of the particles on the surrounding fluid and on each other, i.e. van der Waals forces, and predict significantly less collision between particles of dissimilar sizes (Jackson and Burd, 1998). Rectilinear kernels appear, therefore, to generate a much stronger coagulation effect and vertical flux (Jackson, 2001).

Despite being the dominant process in controlling vertical carbon flux from biological production (Jackson et al., 2005) there has been almost no implementation of aggregation models on 3D oceanic-biogeochemical models. Gehlen et al. (2006) presented a first attempt by employing Kriest's (2002) model to extend the simple parameterisation of aggregation used in the global biogeochemical model of Aumont and Bopp (2006) into its detritus pool. Dadou et al. (2001) developed a 1-D biogeochemical model to reproduce organic matter fluxes in the NW African Upwelling zone and parameterised aggregation as a second-order process. Herein we use a biogeochemical model in a regional setup of the NW African Upwelling System and consider both phytoplankton and detritus as the constituents of aggregates. The model response to changes in porosity, maximum aggregate size and stickiness is evaluated. The purpose is not to detect which aggregate composition (dense or porous) represents the particle behaviour in the ocean, but rather to find out which set of parameters like aggregate density, i.e. settling velocity, and remineralisation rate give the best estimate of deep fluxes with the same or similar surface productivity pattern. We then compare the simulated particle number concentrations and the particle size spectra with those as measured by the camera profiles. The predicted organic carbon fluxes are also compared to the recordings of sediment traps located off Cape Blanc as well as to the fluxes produced by the original biogeochemical model. By bringing the findings from the field measurements like particle camera and settling chamber together with modelling work this paper tries to shed a little light upon the complexities surrounding the particle transformations in the water column.

\section{Methods}

\subsection{Sediment trap, particle camera and settling chamber measurements}

We refer to Fischer and Karakaş (2009), for the sediment trap characteristics and analysis of the collection. The particle camera (ParCa) system we used was a modified version of the system described in Ratmeyer and Wefer (1996). It consisted of a NIKON Coolpix digital camera with a 3.34 megapixel resolution. A strobe mounted perpendicular to the camera illuminated the water. Each image recorded the particles within a volume of 12.41 . A SeaBird 36 telemetry unit and a SeaBird 19 CTD (equipped with an oxygen sensor and a CHELSEA flourometer) measured pressure and triggered the ParCa at a depth interval of ten meters while it was lowered at $0.3 \mathrm{~m} \mathrm{~s}^{-1}$. To prevent interference with ambient light, the ParCa system was only deployed at night. The images were analysed using the image analysis software 'Optimas' (Meyer Instruments, Houston, USA). The color images were converted into 8 bit gray scale images. The analysis returned the area and abundance of each aggregate in an image. We calculated the spherical equivalent diameter (ESD) of the each aggregate assuming that the particles are circular. We calculated the particle size spectrum $n$ as a function of particle diameter $d$ by dividing the concentration of particles $(\Delta C)$ in a given small size range $(\Delta d): n=\Delta C / \Delta d$. We found the usable size range to be between 140 and $6500 \mu \mathrm{m}$ with the lower bound set by optical limitation and the upper bound by the concentration of the large aggregates. The data presented in this study originate from our RV Merian cruise off Cape Blanc in March 2007.

Sinking speed measurements were carried out with the $1000 \mathrm{~m}$ depth rated, mid-size inspection class ROV "MARUM Cherokee", manufactured by Sub-Atlantic/Scotland. In order to measure in situ sinking speeds of marine snow aggregates, the vehicle was equipped with a settling chamber which was built in the context of a similar device used by Pillskaln et al. (1998). The chamber is made of a $30 \mathrm{~cm} \times 30 \mathrm{~cm} \times 40 \mathrm{~cm}$ plexiglass box that can be opened and closed sideways with the aid of the ROV's manipulator. A collimated light source, mounted on the port side of the vehicle, provides a slab of light of $12 \mathrm{~cm}$ width through the centre of the chamber. In order to measure the distance a particle travelled through time, a caliper was fixed in the middle of the box. Sinking aggregates in a sample volume of $20 \mathrm{~cm} \times 12 \mathrm{~cm} \times 17 \mathrm{~cm}$ or $4.08 \mathrm{l}$, were recorded with the aid of the ROV's video camera stored on DV tapes. After reaching the depth of interest, the vehicle would fly a few meters straight forward, with opened chamber door. The vehicle would then stop and maintain depth while the door is closed. As described in Pillskaln et al. (1998), minor to moderate levels of turbulent motion of particles in the chamber were inevitable. Thus, we waited 10-15 min before we started to record vertically sinking particles, which took $20-40 \mathrm{~min}$.

The sinking speed measurements were carried out at station GeoB $12914\left(21^{\circ} 19,89 \mathrm{~N} ; 18^{\circ} 49,60 \mathrm{~W}\right.$, hereafter referred to as SC) during RV Poseidon Cruise 365 off Cape Blanc/Mauritania in four depth levels: $50 \mathrm{~m}, 100 \mathrm{~m}, 250 \mathrm{~m}$ and $400 \mathrm{~m}$. The depths were chosen after a particle abundance profile, acquired by the vertically profiling camera system ParCa. The $50 \mathrm{~m}$ depth level represents both the particle and chlorophyll maximum. At $100 \mathrm{~m}$ water depth, a distinct particle minimum is found. A small subsurface maximum can be found around $250 \mathrm{~m}$ while at $400 \mathrm{~m}$, particle concentrations are comparably lower.

\subsection{The model}

We employed the Regional Oceanic Modelling System (ROMS) and its coupled ecosystem model to study aggregate fluxes in the NW African upwelling zone. ROMS uses a generalised terrain-following coordinates in vertical and orthogonal curvilinear coordinates in the horizontal to solve three-dimensional, free surface, hydrostatic, primitive equations (Shchepetkin and McWilliams, 2005). The ecosystem component of ROMS consists of seven state variables: nitrate, ammonium, phytoplankton, a dynamic phytoplankton chlorophyll/carbon ratio, zooplankton, and small and large detritus (Gruber et al., 2006). Large detritus in this original model is produced by the coagulation of phytoplankton and small detritus based on a simple particle density function. In order to implement the aggregation model we removed large detritus compartment and defined a new compartment representing aggregate number. The evolution of any state variable $\left(C_{i}\right)$ follows the conservation equation:

$\frac{\partial C_{i}}{\partial t}=-\nabla \cdot\left(u C_{i}\right)-A_{\rho} \nabla^{2} C_{i}+\frac{\partial}{\partial z}\left(K_{\rho} \frac{\partial C_{i}}{\partial z}\right)+Q\left(C_{i}\right)$

where $A_{\rho}$ is the horizontal eddy diffusion coefficient, $K_{\rho}$ is the vertical turbulent diffusion coefficient and $Q$ is the source minus sink term. The relationship between the different compartments of the model is outlined in Fig. 1. The parameter values of the model that are given in Gruber et al. (2006), represent a eutrophic coastal ecosystem and were unchanged in this study except for the particle remineralisation rate. 


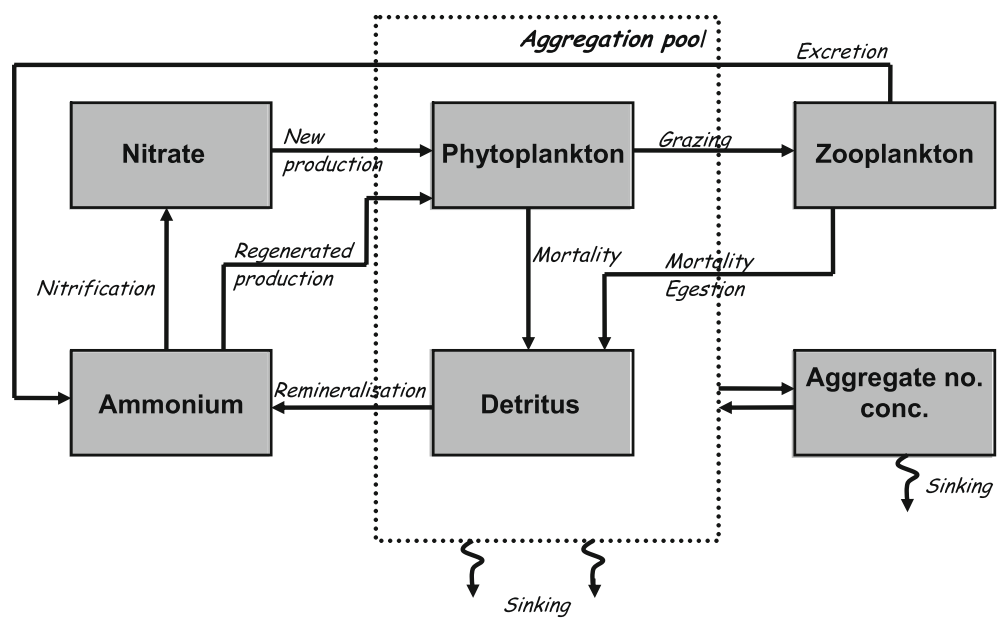

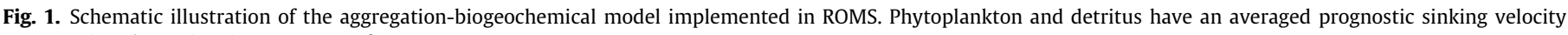
representing the entire size spectrum of aggregate mass.

The aggregation processes and aggregate sinking are based on a continuous size spectrum of aggregates following Kriest (2002). Unlike Gehlen et al. (2006), not only detritus but also phytoplankton coagulate to produce aggregates. The total number of particles is treated as a separate state variable, which allows dynamical representation of average particle size and sinking rate. Aggregate size spectrum is defined by McCave (1984):

$P(d)=A d^{-\varepsilon}$

where $d$ denotes aggregate diameter. $A$ and $\varepsilon$ are evaluated from total particle mass and numbers (Kriest and Evans, 1999). The decrease in density with increasing aggregate size can be expressed by using fractal scaling in which the mass, $M$, relates to the size of an aggregate by:

$M=B d^{5}$

where $\zeta$ is the fractal dimension of the aggregate (Jackson and Burd, 1998). The values of $\zeta$ change between 1.3 and 2.3 (Jackson, 2005), with small values indicating more porous structure. Similarly, particle sinking speed is also represented by a two parameter power law as a function of $d$ (Kriest, 2002):

$W=C d^{\eta}$

with $\eta$ representing sinking exponent. Minimum mass and sinking rates are therefore prescribed depending on cell size.

Disaggregation is not considered in Kriest's model but there exists a maximum size that an aggregate can reach, which also restricts aggregate settling rates to an upper limit. A universal formulation of disaggregation does not exist due to the variety of processes involved which are not completely understood, like physical or biological fragmentation, zoplankton feeding, and microbial activity. Stemmann et al. (2004) considered flux feeding zooplankton in their numerical study and found that it has a significant effect on particle fluxes above $500 \mathrm{~m}$ depth. In this study we kept the model as simple as possible and avoided involving another zooplankton compartment in order to make comparison to the original biogeochemical model (Gruber et al., 2006; Fischer and Karakaş, 2009) possible. We therefore parameterised disaggregation by defining a disaggregation rate which is dependent on the number of aggregates and on the sinking velocity:

$\psi(z)=\operatorname{NOS}(z)\left[\frac{1}{\varepsilon(z)-1-\zeta}-1\right] \kappa_{0} e^{-\lambda z}$ where NOS is the total number concentration of aggregates, $\varepsilon$ is the slope of particle size distribution and $\kappa_{0}$ is an empirical rate constant. Similar to Dadou et al. (2001), disaggregation rate varies exponentially with depth, $z$. The disaggregation term maintains the mass while forcing the model to produce more, smaller and slower aggregates.

Integration of Eqs. (3), (2), (4), and (2) over the size range gives average settling velocity of mass and number of particles. Aggregation equations due to turbulent shear and differential settlement are solved as described in Kriest (2002) over the entire range of size spectra.

The model area stretches between $5^{\circ} \mathrm{N}-41^{\circ} \mathrm{N}$ and $30^{\circ} \mathrm{W}-5.5^{\circ} \mathrm{W}$, covering the entire region off NW Africa. The grid as well as forcing, initial and boundary data are produced by using ROMSTOOLS package (Penven et al., 2008). The topography is derived from 1-min GEBCO data and interpolated to a $20 \mathrm{~km}$ horizontal grid. The vertical grid has 32 sigma levels with resolution getting coarser at depth. Initial state and boundary fluxes for temperature, salinity, momentum and nutrients were derived from the World Ocean Atlas 2005 (Locarnini et al., 2006; Antonov et al., 2006; Garcia et al., 2006). Setting into motion from a cold start, the physical model was forced by monthly climatologies of Comprehensive OceanAtmosphere Data Set (Da Silva et al., 1994) during a spin-up period of 3 years, which was followed by the 6-hourly NCEP reanalysis-2 forcing (Kanamitsu et al., 2002) for the years 2002 and 2003.

As in Kriest (2002), prescribed particle mass and sinking factors and mass and sinking exponents in the simulations represent porous and dense aggregates, which are found in the ocean (Table 1). Remineralisation rate was constant but proportional to the sinking velocity of smallest aggregate size, i.e. $0.02 \mathrm{~mm}$. Porous aggregates therefore remineralised four times faster than the dense aggregates. By setting remineralisation rate fixed to the aggregate sinking velocity a relatively similar productivity and export rate is provided in all experiments. Using these aggregate characteristics Table 2 shows the list of sensitivity experiments carried out with

Table 1

Mass and sinking characteristics of modelled aggregates.

\begin{tabular}{|c|c|c|c|c|c|}
\hline \multirow[t]{2}{*}{ Aggregate porosity } & \multicolumn{2}{|c|}{$\begin{array}{l}\text { Mass } \\
\text { Scaling } \\
\end{array}$} & \multicolumn{2}{|c|}{ Sinking } & \multirow[t]{2}{*}{ Remineralisation rate $\left(\mathrm{d}^{-1}\right)$} \\
\hline & $B$ & $\zeta$ & C & $\eta$ & \\
\hline Dense & 5700 & 2.28 & 942 & 1.17 & 0.005 \\
\hline Porous & 273 & 1.62 & 132 & 0.62 & 0.02 \\
\hline
\end{tabular}


Table 2

List of model experiments with corresponding aggregate properties.

\begin{tabular}{lllll}
\hline $\begin{array}{l}\text { Experiment } \\
\text { code }\end{array}$ & $\begin{array}{l}\text { Aggregate } \\
\text { porosity }\end{array}$ & $\begin{array}{l}\text { Maximum } \\
\text { aggregate size } \\
(\mathrm{mm})\end{array}$ & Stickiness & Disaggregation \\
\hline D5S & dense & 5 & 0.5 & No \\
P1S & porous & 1 & 0.5 & No \\
P1nS & porous & 1 & 0.05 & No \\
D04nS & dense & 0.4 & 0.05 & No \\
P1nS-disagg & porous & 1 & 0.05 & Yes \\
\hline
\end{tabular}

varying maximum aggregate size and stickiness values. The disaggregation term is switched on in one experiment to assess its effect on particle number spectra and on particle fluxes. While maximum aggregate size ranged between 0.4 and $5 \mathrm{~mm}$, the stickiness coefficient was set to 0.5 and 0.05 . Stickiness is a parameter which defines the probability of two colliding particles staying together, the value of which depends strongly on the concentration of mucus around particles (Dam and Drapeau, 1995). By reducing the stickiness one order of magnitude, we wanted to restrict the excessive collisions that the rectilinear kernel produces in comparison to a curvilinear formulation. In total five experiments were carried out employing: dense, and sticky aggregates with $5 \mathrm{~mm}$ maximum size (D5S), porous and sticky aggregates with $1 \mathrm{~mm}$ maximum size (P1S), porous and non-sticky aggregates with $1 \mathrm{~mm}$ maximum size (P1nS), dense and non-sticky aggregates with $0.4 \mathrm{~mm}$ maximum size (D04nS) and finally porous and non-sticky aggregates with $1 \mathrm{~mm}$ maximum size and disaggregation turned on (P1nS-disagg).

\section{Results and discussion}

\subsection{Comparison of surface chlorophyll fields to the satellite data}

The validation of the generated physical fields by the model has been discussed in Karakaş et al. (2006) and Marchesiello and Estrade (2007). In Fig. 2, we illustrate mean surface chlorophyll distribution from SeaWiFS and model experiments for the year 2002. The general pattern of chlorophyll distribution is similar in all simulations to the satellite data and there is very little discrepancy. This is not surprising because by setting the remineralisation rate proportional to the sinking velocity for dense and porous approximations, the remineralisation length scale is more or less maintained, which causes similar amounts of nitrogen to be recycled back to the nutrient pool for surface productivity.

Cape Blanc filament is reproduced successfully in all experiments. However, the model solution gives a diffuse gradient in the onshore-offshore direction. In general chlorophyll fields in dense experiments present slightly higher chlorophyll concentrations than porous experiments. Among the two dense experiments the one with smaller maximum aggregate (D04nS) size generated somewhat more chlorophyll along the coast. In the coastal transition zone (CTZ) the fields appear to be overestimated in the experiment D5S. The chlorophyll concentration in this simulation is almost two times higher $\left(0.8 \mathrm{mg} \mathrm{Chl} \mathrm{m}^{-3}\right)$ than the observed value $\left(0.4 \mathrm{mg} \mathrm{Chl} \mathrm{m}^{-3}\right)$ at the mesotrophic sediment trap site $\mathrm{CB}$. Other experiments, on the other hand, give a good match at $C B$ despite exaggerated values being reproduced within the CTZ to the north of Cape Bojador. The concentrations along the coast, on the other hand, are rather poorly represented in all modelled fields, which, to a considerable extent, resulted from the relatively coarse grid resolution.

\subsection{Particle size spectrum and number distribution}

Fig. 3 illustrates particle size spectrum against equivalent spherical diameter (ESD) at different depth levels as observed by the camera profiles and from the model experiments. Both observed and simulated plots show a decrease in abundance with increasing diameter, which is a typical pattern (Guidi et al., 2008; Stemmann et al., 2008). Note that the particle camera can capture particles of minimum $140 \mu \mathrm{m}$ size and therefore particles of smaller size cannot be shown in Fig. 3a. Even though there does not seem to be a difference in observed particle abundances at different depths, the slope of curves varies. The slope at $500 \mathrm{~m}$ for instance is steeper than the one at $1000 \mathrm{~m}$. At $200 \mathrm{~m}$ depth, however, strong oscillations are noticeable in particle abundance. The modelled size spectra present a very diffuse pattern compared to the observations and a diverse range of abundances. Almost in all experiments the slope of the curves increases with reducing depth. The dense approximation, nevertheless, appears to generate more moderate slopes. In fact we could have obtained a better match of size spectra by limiting the model fractal dimension to vary within a range which is found in observations because the fractal dimensions of particles are estimated from the measured slope of particle spectra (Burd and Jackson, 2002). In our experiments the fractal dimension was obtained from the total particle mass and numbers (Kriest and Evans, 1999).

Total particle numbers at this measurement site show a sharp decrease from $30 \mathrm{l}^{-1}$ at the surface to $2 \mathrm{l}^{-1}$ at around $175 \mathrm{~m}$ and record another maximum at $500 \mathrm{~m}$ with values around $8 \mathrm{l}^{-1}$ (Fig. 4). While modelled distributions of particles larger than $140 \mu \mathrm{m}$ did not reproduce the peak abundance at the surface, the subsurface maximum was produced in all experiments, even if they were at different depths. This observed subsurface maximum is not uncommon in camera measurements (Nowald et al., 2006) and most probably this maxima indicates an Intermediate Nepheloid Layer (INL) which is generated by the particles eroded from the shelf and upper slope (Karakaş et al., 2006; Fischer et al., this volume). It cannot be justified to claim that this increase in particle numbers in the subsurface could also receive some contribution from aggregation processes because of the inability of the model to reproduce surface particle number concentrations as has been observed in the field. Therefore, whether aggregation could also contribute to this feature in the subsurface or have an impact on the oxygen minimum zone that is observed in similar depths (Fischer et al., this volume) remains an issue for further investigation.

Because particle aggregation in the model is controlled by particle collisions due to turbulent shear and differential settlement it could be also interesting to see the mean profile of shear against total particle numbers (Fig. 5). The mean shear at the site CB drops sharply under the surface and rises again at $50 \mathrm{~m}$ depth. Because $50 \mathrm{~m}$ corresponds to particle and chlorophyll maximum the influence of this shear increase is not obvious. Only in one experiment with dense aggregates there exists a slight decrease in particle numbers, which could be due to aggregation.

\subsection{Aggregate settling velocity and mass}

In Fig. 6, we show the observed sinking velocities of aggregates by using the settling chamber. A wide span of sinking velocities has been observed with majority around $55 \mathrm{~m} \mathrm{~d}^{-1}$. Modelled aggregates are also transported into the deep ocean with a range of sinking velocities depending on their size and porosity. Fig. 7 shows averaged sinking velocities from the simulations for the year 2002 at the mesotrophic sediment trap site CB. Large, dense and sticky aggregates reach up to $400 \mathrm{~m} \mathrm{~d}^{-1}$ velocity below $1000 \mathrm{~m}$ depth (D5S). The aggregates with $1 \mathrm{~mm}$ size sink a lot slower, i.e. with $30 \mathrm{~m} \mathrm{~d}^{-1}$ at their fastest settling (P1S, P1nS and P1nS-disagg). Smaller aggregates, however, sink with $22 \mathrm{~m} \mathrm{~d}^{-1}$ velocity (D04nS). The stickiness does not play any role in determining the maximum sinking velocity but it regulates the depth at which aggregates at- 

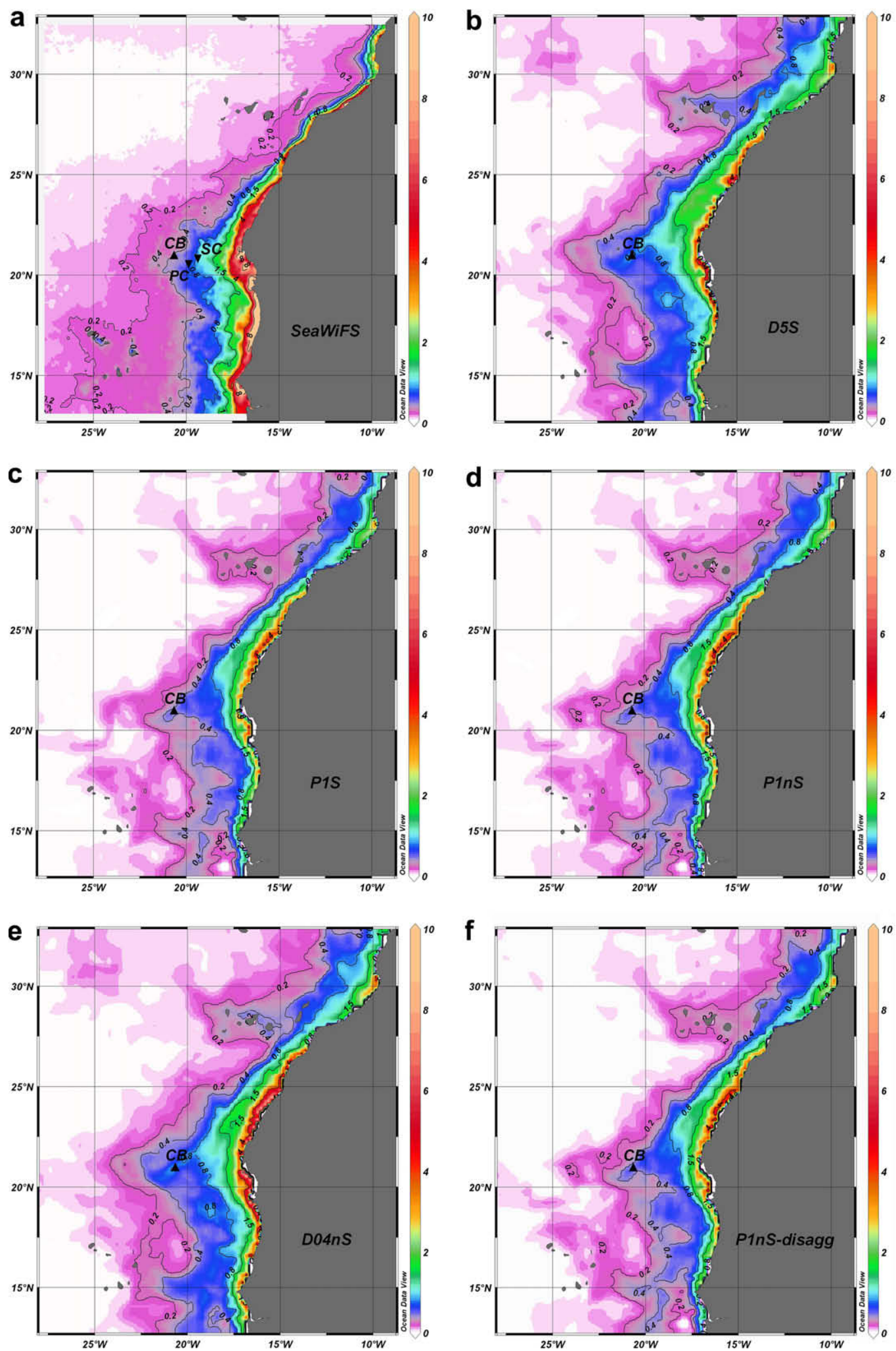

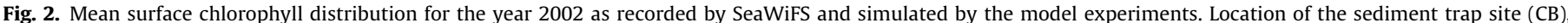
particle camera deployment site (PC) and settling chamber deployment site (SC) are also shown: (a) SeaWiFS, (b) D5S, (c) P1S, (d) P1nS, (e) D04nS and (f) P1nS-disagg.

tain this velocity. Because of the smaller number of collisions that result in coagulation, non-sticky aggregates $(\mathrm{P} 1 \mathrm{nS})$ arrive at their peak size, as well as peak velocity, in deeper layers than sticky aggregates (P1S). It is interesting to note that when the disaggregation term is activated, sinking velocity curve presents a more linear pattern, which is similar to the one estimated by Berelson (2002). As shown by Kriest and Oschlies (2008), such a strong increase in sinking speeds that we observed with different model experiments appears to be a typical characteristic of power law size spectra, when it is described all along the water column. One should notice 

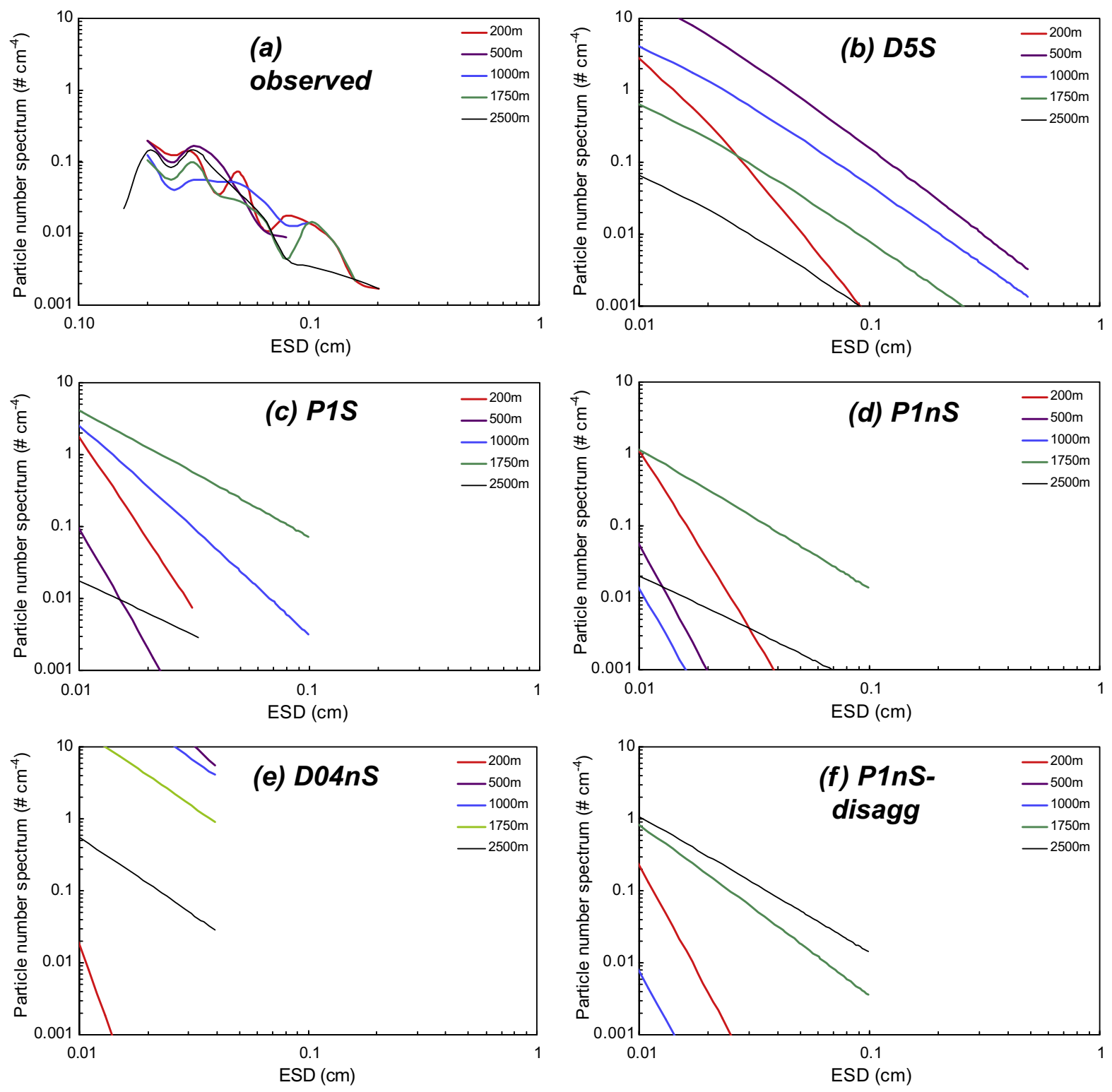

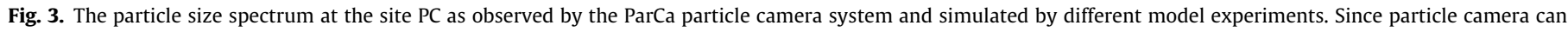
resolve sizes larger than $140 \mu \mathrm{m}$, the smaller sizes are not shown in the observed spectrum: (a) SeaWiFS, (b) D5S, (c) P1S, (d) P1nS, (e) D04nS and (f) P1nS-disagg.

that the sinking rates given here are the averaged rates for the entire particle size spectrum. We measured a similar range of sinking velocities, i.e. $34-43 \mathrm{~m} \mathrm{~d}^{-1}$ by consecutive particle camera deployments in the region (Fischer et al., this volume).

The in situ measurements, nevertheless, do not show any indication of size dependency on particle sinking. A very weak or no relationship between diameter and sinking speed has been previously reported for in situ collected aggregates (Alldredge and Gotschalk, 1988). A stronger dependency, however, has been reported for aggregates that are produced on the roller table by differential settlement from that of aggregates produced by turbulent shear (Kriest, 2002). Our observations were carried out down to $400 \mathrm{~m}$ depth where turbulent shear is the dominant process, which could also explain why the model fails to reproduce particle size spectrum for the upper layers.

In Fig. 8, we show the distribution of total aggregate mass along the $21^{\circ} \mathrm{N}$ longitudinal cross section off Cape Blanc. Model simulations show significant differences regarding aggregate concentration. With dense aggregates of $5 \mathrm{~mm}$ size (D5S), concentrations of up to $2.5 \mathrm{mMol} \mathrm{N} \mathrm{m} \mathrm{m}^{-3}$ cover the entire water column due to the very high sinking velocity of these aggregates. Although not as much as D5S, smaller and non-sticky dense aggregates (D04nS) also generated enhanced mass. The simulations with porous aggregates resulted in much less aggregate mass, increasing towards surface and in onshore direction. The experiments with both sticky and non-sticky porous aggregates of $1 \mathrm{~mm}$ maximum size (P1S, P1nS and P1nS-disagg) had similar amounts of mass near the surface. However, the experiment P1S showed higher deep water concentration than P1nS due to its stickiness which allows faster aggregation and penetration to the deep ocean. Among all, the smallest aggregate mass in the deep layers was produced when the disaggregation term was switched on (P1nS-disagg).

\subsection{Modelled organic carbon fluxes to the depth and their variation}

Over the deployment period between April 2002 and May 2003 the mean observed organic carbon fluxes at the mesotrophic sediment trap site CB fall from $1.9 \mathrm{~g} \mathrm{~m}^{-2} \mathrm{y}^{-1}$ to $1.7 \mathrm{~g} \mathrm{~m}^{-2} \mathrm{y}^{-1}$ between 


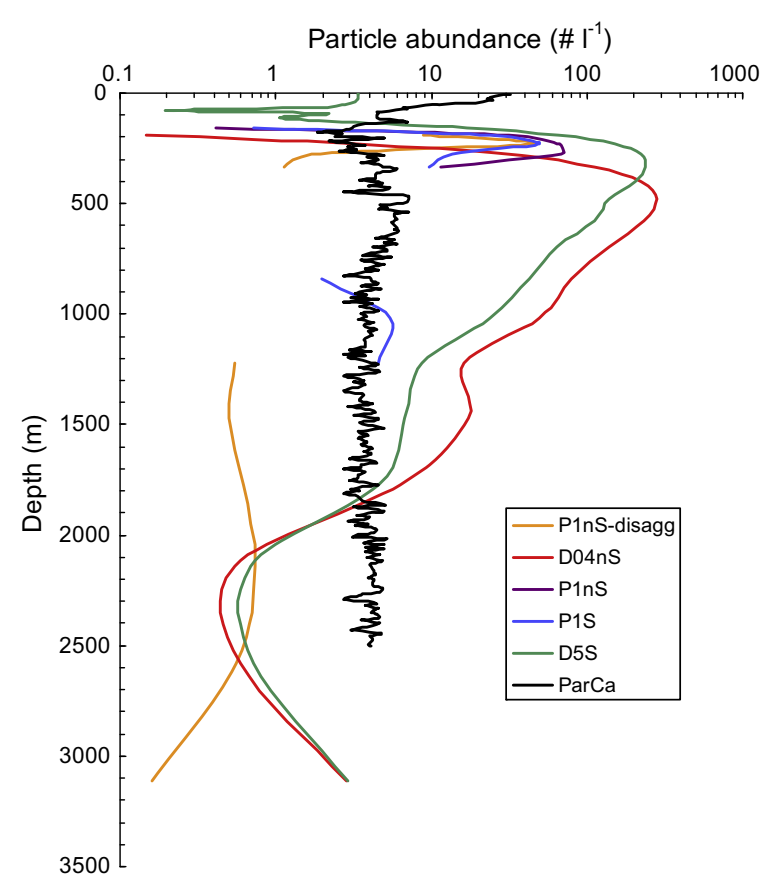

Fig. 4. Observed and modelled particle abundances $\left(\# \mathrm{l}^{-1}\right)$ at the site PC. Note that concentrations less than 0.1 are not shown for clarity of presentation.

$1228 \mathrm{~m}$ and $3606 \mathrm{~m}$ trap depths. This rate of reduction is comparable to previous observations of Bory et al. (2001), which were conducted as part of EUMELI program. These authors report a much lower decrease in POC fluxes with depth than the one calculated from the Martin et al. (1987) relationship. Fig. 9 shows simulated mean organic carbon fluxes with the model experiments. The experiments with dense aggregates (D5S and D04nS) give 2-4 order of magnitude higher fluxes, whereas porous aggregates could estimate the measured values better. The simulation with porous and non-sticky aggregates of $1 \mathrm{~mm}$ size (P1nS) for instance, gives 4 and 2.5 times larger fluxes for the upper and lower traps, respectively. The best estimate, however, is produced when the disaggregation was included. In this case the same type of aggregates gives almost the same value of flux at the upper trap and only $0.9 \mathrm{~g}$ less flux at the deep trap.

Kriest (2002) compared the results from her 1-D model to the observations and argued that porous parameterisation could represent the marine snow better. Because the remineralisation rates of dense and porous particles are different in our experiments, it is

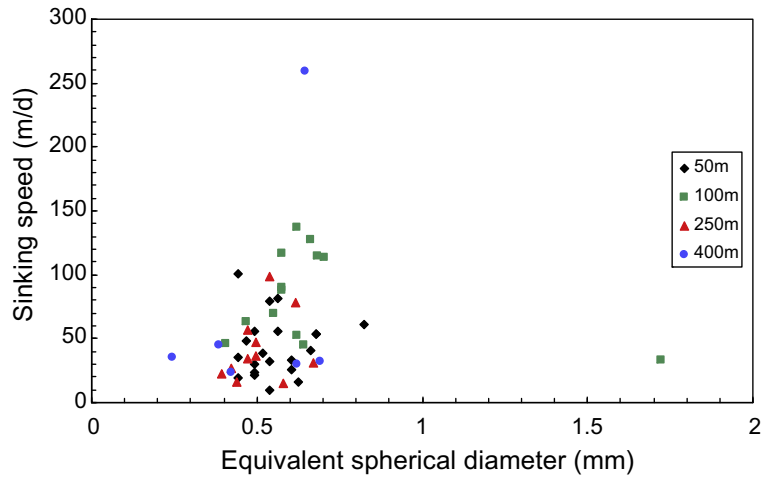

Fig. 6. In situ measurements of particle sinking velocity $\left(\mathrm{m} \mathrm{d}^{-1}\right)$ at the site SC by the settling chamber versus equivalent spherical diameter $(\mathrm{mm})$.

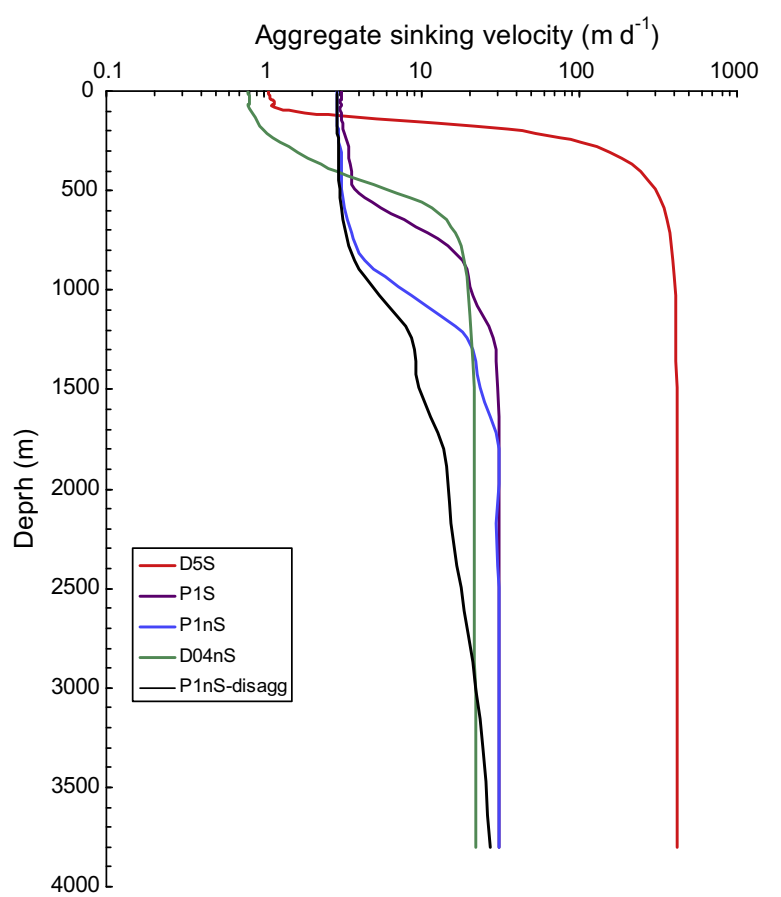

Fig. 7. Modelled mean aggregate sinking velocity for the year 2002 along the depth at the mesotrophic sediment trap site CB.
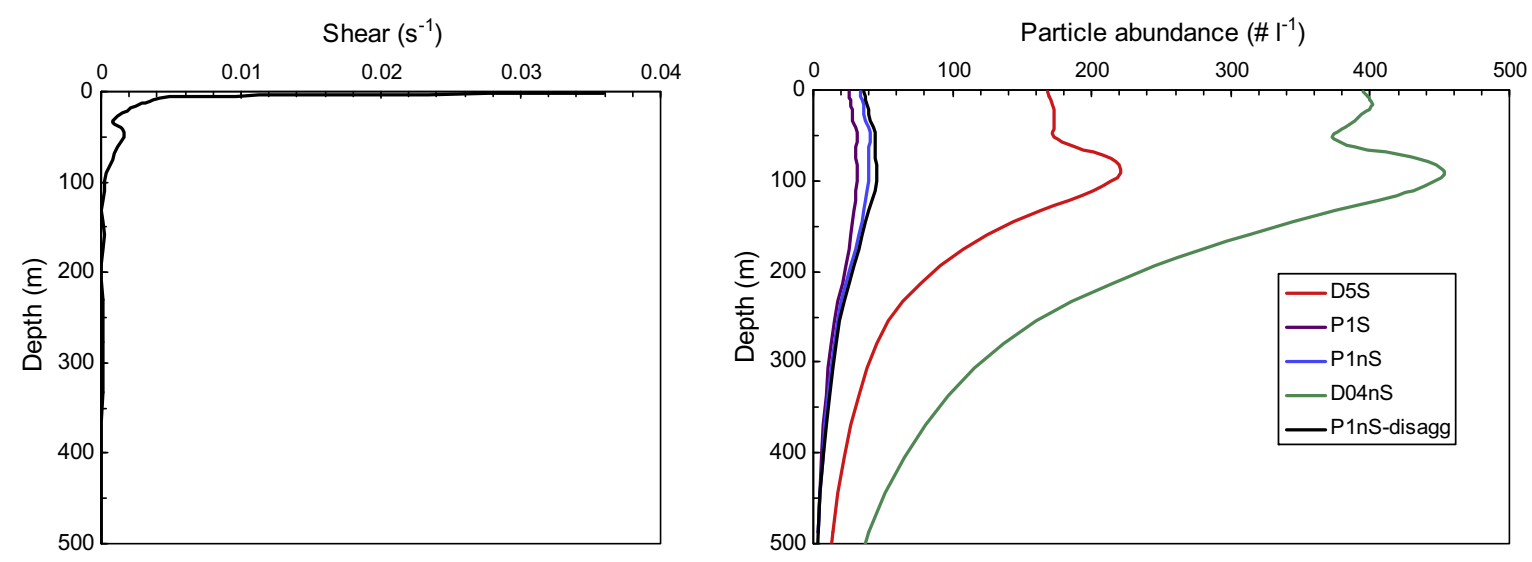

Fig. 5. Modelled annual mean shear $\left(\mathrm{s}^{-1}\right)$ and annual mean particle abundances $\left(\# \mathrm{l}^{-1}\right)$ at the site $\mathrm{CB}$. 
a

Aggregate Mass [mMol N m-3]
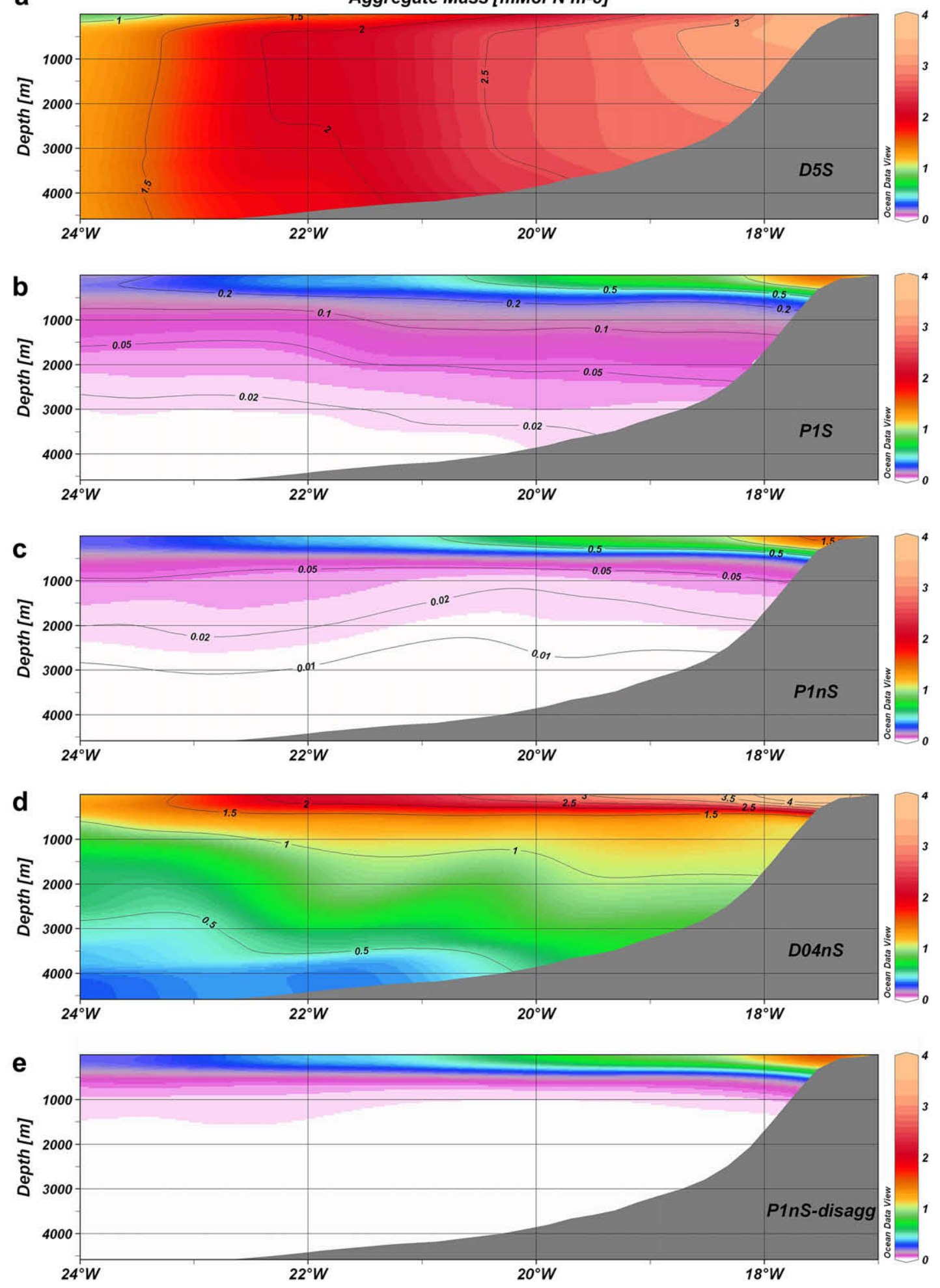

Fig. 8. Modelled mean aggregate mass for the year 2002 along $21^{\circ} \mathrm{N}$ longitudinal cross section: (a) D5S, (b) P1S, (c) P1nS, (d) D04nS and (e) P1nS-disagg.

difficult from our study to conclude which type of aggregate fits the flux observations better. Due to the unknowns and complexity involved in the validation of remineralisation we posed surface productivity as a constraint, and gave priority to the representation of surface chlorophyll fields. This is because independent from how well the simulated fluxes of a model match the observations, their validity is questionable unless surface productivity is also repre- sented reasonably well by the model. We therefore tried to reproduce similar surface chlorophyll fields by using a similar remineralisation length scales for both dense and porous aggregates, i.e. by setting settling velocity proportional to the remineralisation rate. In this context looking at these results one can suggest that when disaggregation is included the best set of parameters which represent aggregate characteristics in this upwelling region 


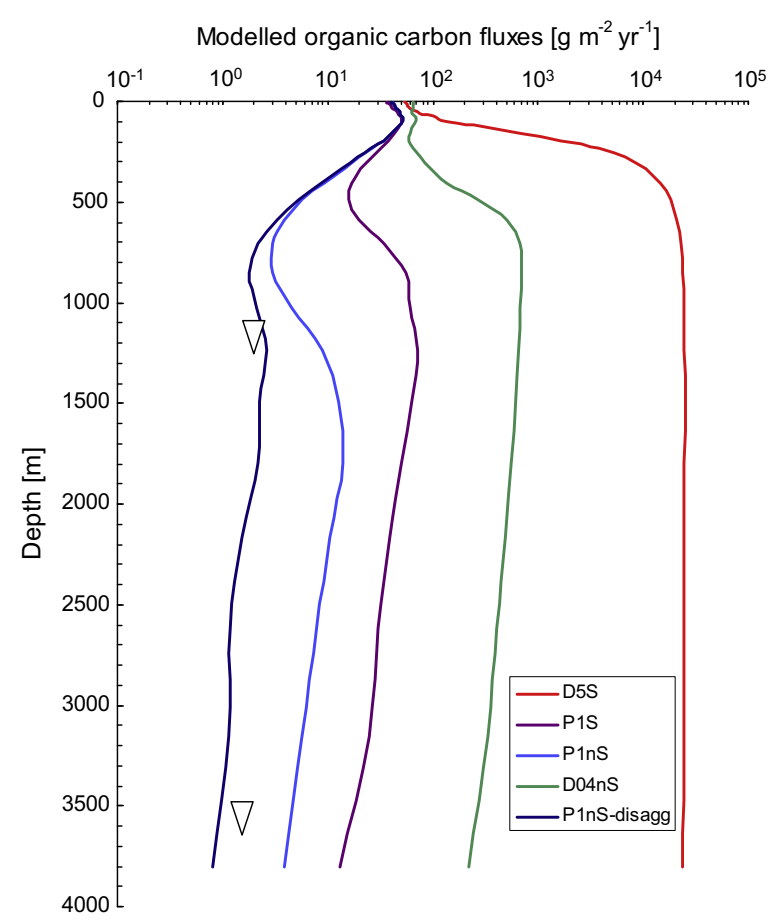

Fig. 9. Modelled mean organic carbon fluxes at the sediment trap site CB between May 2002 and April 2003. Recorded flux values for the traps, which are located at $1228 \mathrm{~m}$ and $3606 \mathrm{~m}$ depths, for this period are shown by the inverted triangle. The analysis method of the flux data is explained in Fischer and Karakaş (2009). Colours represent different model experiments.

was the porous approximation with a remineralisation rate of $0.2 \mathrm{~d}^{-1}$. In fact, as can be seen in Fig. 3 , the porous aggregates with disaggregation give a very similar particle size spectrum and slope in deep water to the observation. It is also worth noting that observed aggregate sizes hardly exceed $1 \mathrm{~mm}$ (see Figs. 3 and 6). Because aggregation models with rectilinear kernels produce more collisions between particles and therefore higher fluxes than those with the curvilinear formulations (Jackson, 2001), one can argue that the curvilinear formulations have the potential to produce more realistic fluxes. In our simulations, we could get the best agreement to the observed fluxes with reduced stickiness, which decreased vertical fluxes as much as one order of magnitude.

The modelled fluxes with small porous, non-sticky aggregates produce a steep reduction of fluxes in subsurface waters due to particle remineralisation, which is followed by an increase of fluxes in deeper layers. Such an increase could be the result of lateral transport of organic matter or a transient pulse from above. Aggregation could therefore indirectly contribute to the observations of flux increase with depth. We were able to catch such a pulse of particle settling in one of our particle camera deployments off Cape Blanc (see Fischer et al., this volume).

In order to evaluate the impact of implementing an aggregation model into the original biogeochemical model, in Fig. 10 we plotted the flux curves produced by the original model of Gruber et al. (2006), as well as of Fischer and Karakaş (2009), who modified the Gruber's model by using realistic mean sinking velocities. The velocities in their work were seasonally changing and they were specified from the estimations based on the time difference between chlorophyll maxima at the surface and sedimentation peaks at the deep trap. While the fluxes generated by the original model overestimated the upper and underestimated the deeper recorded flux values, the model with modified sinking velocity could capture the deep flux but still overestimated the upper flux. With the implementation of aggregation the prediction capability of the original model has therefore been significantly improved.

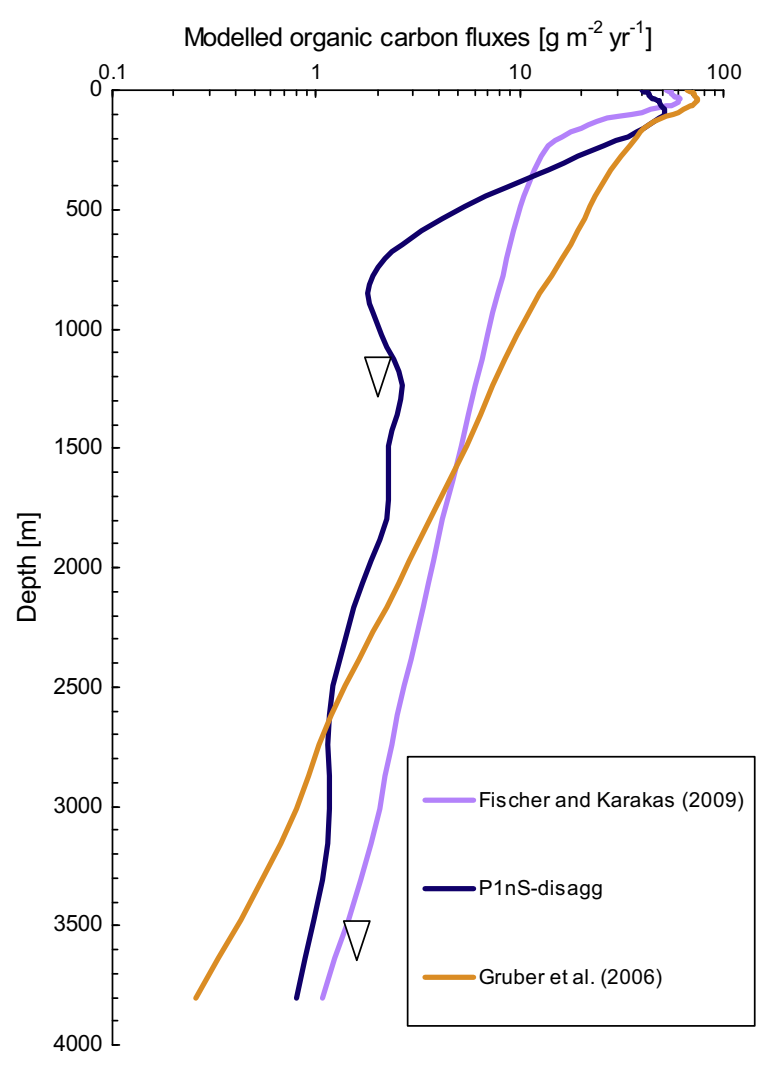

Fig. 10. Same as Fig. 9 but results from the biogeochemical model of Gruber et al. (2006) and Fischer and Karakaş (2009) along with the flux curve from the aggregation model with disaggregation term.

The role of particle decay rate in the vertical distribution of organic carbon is crucial but far from being trivial to investigate. Kriest and Oschlies (2008) and Stemmann et al. (2004) give a detailed account and discussion of the processes involved. Ploug and Grossart (2000) argued that the decay rate may be constant for particle size ranging between 1 and $6 \mathrm{~mm}$. There exists, however, no evidence of constant decay rate for particles smaller than $1 \mathrm{~mm}$. Besides, Moriceau et al. (2007) report that silica dissolution rates of freely suspended diatoms were more than two times higher than aggregated ones. In most biogeochemical models with different particle size classes this issue is taken into account and large particles remineralise slower than small particles, which also helps to attain a flux curve which is close to the power-law attenuation of flux, i.e. Martin's curve (Gregg et al., 2003; Gruber et al., 2006). However, like in the previous modelling studies of aggregation we also used a size-independent remineralisation rate in this work, although this rate was different in dense and porous aggregates. Using a size-dependent decay rate would modify the particle size spectrum as well as the vertical flux curve. Whether it has the potential to increase the surface productivity which is weakly represented in our model remains to be investigated.

The reason why the model could produce a relatively good estimate of deep water fluxes although the surface particle size spectrum was in disagreement with camera measurements could be the stickiness. In most experiments we reduced the stickiness in order to avoid the exaggerated coagulation effect of rectilinear kernel. This however resulted in very small particles in the surface layers, which were unable to increase their size with collision. Particle flux exported out of surface layers was still sufficient to provide a good fit of deep fluxes. The concentration of transparent exopolymeric particles (TEP) affects the stickiness (Jackson, 1995; Passow, 2002) and the variation of stickiness during a bloom has 
been reported elsewhere (Dam and Drapeau, 1995). Parameterising this variation has not been covered in our study but would modify the results.

\section{Summary and conclusions}

Various model experiments were carried out by applying an aggregation model into the phytoplankton and detritus compartments of a biogeochemical model. The model was based on a continuous size spectrum of aggregates. The simulations covered maximum aggregate sizes ranging between 0.4 and $5 \mathrm{~mm}$. Both porous and dense aggregates were considered with reduced stickiness in order to yield limited collision between particles. One experiment also involved a disaggregation term to reduce the size of aggregates and produce more particles that sink slower. Setting the remineralisation rate proportional to the sinking velocity of smallest particles generated similar distributions in all experiments and a relatively good match of surface chlorophyll fields to the satellite data. The following conclusions can be drawn from the simulation results in the water column:

- The porous approximation with disaggregation and reduced stickiness gave the best agreement with the measurements at the mesotrophic sediment trap site CB off Cape Blanc provided that the particle decay rate is $0.2 \mathrm{~d}^{-1}$.

- The model failed to reproduce observed particle size spectrum in particular for the upper layers. Simulation of particle size spectra could be improved by limiting the fractal dimension in the model.

- The rectilinear aggregation kernels could be less appropriate for flux predictions due to exaggerated collision rates that they generate.

- Disaggregation is a crucial mechanism in predicting the deep water fluxes and particle size spectra.

- In order to improve the representation of aggregation dynamics, variation in stickiness and size dependent remineralisation could be the areas that should be focussed on in further numerical studies of aggregation.

\section{Acknowledgements}

We thank anonymous referees for their constructive comments that helped to improve the manuscript significantly. The numerical experiments were partly carried out on IBM pSeries 690 Supercomputer of Norddeutscher Verbund für Hoch- und Höchstleistungsrechnen (HLRN). This research was funded by the German Research Foundation (DFG) - Centre for Marine Environmental Sciences (MARUM).

\section{References}

Alldredge, A.L., Gotschalk, C., 1988. In situ settling behaviour of marine snow. Limnology and Oceanography 33 (3), 339-351.

Alldredge, A.L., Gotschalk, C.C., 1989. Direct observations of the mass flocculation of diatom blooms: characteristics, settling velocities and formation of diatom aggregates. Deep Sea Research 36 (2), 159-171.

Antonov, J.I., Locarnini, R.A., Boyer, T.P., Mishonov, A.V., Garcia, H.E., 2006. World Ocean Atlas 2005. In: Levitus, S. (Ed.), NOAA Atlas NESDIS 62, Salinty, vol. 2. US Government Printing Office, Washington DC. 182 pp..

Aumont, O., Bopp, L., 2006. Globalizing results from ocean in situ iron fertilization studies. Global Biogeochemical Cycles 20 (2), GB2017.

Berelson, W.M., 2002. Particle settling rates increase with depth in the ocean. DeepSea Research Part II 49, 237-251.

Bory, A., Jeandel, C., Leblond, N., Vangriesheim, A., Khripounoff, A., Beaufort, L., Rabouille, C., Nicolas, E., Tachikawa, K., Etcheber, H., Buat-Ménard, P., 2001. Downward particle fluxes within different productivity regimes off the Mauritanian upwelling zone (EUMELI program). Deep-Sea Research 48 (10), 2251-2282.

Burd, A.B., Jackson, G.A., 2002. Modeling steady-state particle size spectra. Environmental Science and Technology 36 (3), 323-327.
Da Silva, A., Young, C., Levitus, S., 1994. Atlas of Surface Marine Data 1994. NOAA Atlas NESDIS 6-10, vols. 1-5. US Government Printing Office, Washington DC.

Dadou, I., Lamy, F., Rabouille, C., Ruiz-Pino, D., Andersen, V., Bianchi, M., Garçon, V. 2001. An integrated biological pump model from the euphotic zone to the sediment: A 1-D application in the Northeast tropical Atlantic. Deep-Sea Research Part II 48 (10), 2345-2381.

Dam, H.G., Drapeau, D.T., 1995. Coagulation efficiency, organic-matter glues and the dynamics of particles during a phytoplankton bloom in a mesocosm study. Deep-Sea Research Part II 42, 111-123.

Dilling, L., Alldredge, A.L., 2000. Fragmentation of marine snow by swimming macrozooplankton: a new process impacting carbon cycling in the sea. DeepSea Research Part I 47 (7), 1227-1245.

Fischer, G., Karakaş, G., 2009. Sinking rates and ballast composition of particles in the Atlantic Ocean: implications for the organic carbon fluxes to the deep ocean. Biogeosciences 6, 85-102.

Fischer, G., Reuter, C., Karakas, G., Nowald, N., Wefer, G., this volume. Offshore advection of particles within the Cape Blanc filament, Mauretania: results from observational and modelling studies. Progress in Oceanography.

Garcia, H.E., Locarnini, R.A., Boyer, T.P., Antonov, J.I., 2006. World Ocean Atlas 2005 In: Levitus, S. (Ed.), NOAA Atlas NESDIS 64, Nutrients (phosphate, nitrate silicate), vol. 4. US Government Printing Office, Washington DC. 96 pp.

Gehlen, M., Bopp, L., Emprin, N., Aumont, O., Heinze, C., Ragueneau, O., 2006 Reconciling surface ocean productivity, export fluxes and sediment composition in a global biogeochemical ocean model. Biogeosciences 3 (4), 521-537.

Gregg, W., Ginoux, P., Schopf, P., Casey, N., 2003. Phytoplankton and iron: validation of a global three-dimensional ocean biogeochemical model. Deep-Sea Research Part II 50, 3143-3169.

Gruber, N., Frenzel, H., Doney, S.C., Marchesiello, P., McWilliams, J.C., Moisan, J.R. Oram, J.J., Plattner, G.-K., Stolzenbach, K.D., 2006. Eddy-resolving simulation of plankton ecosystem dynamics in the California Current System. Deep-Sea Research Part I 53 (9), 1483-1516.

Guidi, L., Jackson, G.A., Stemmann, L., Miquel, J.C., Picheral, M., Gorsky, G., 2008 Relationship between particle size distribution and flux in the mesopelagic zone. Deep-Sea Research Part I 55 (10), 1364-1374.

Jackson, G.A., 1995. Comparing observed changes in particle size spectra with those predicted using coagulation theory. Deep-Sea Research Part II 42, 159-184.

Jackson, G.A., 2001. Effect of coagulation on a model planktonic food web. Deep-Sea Research Part I 48, 95-123.

Jackson, G.A., 2005. Coagulation theory and models of oceanic plankton aggregation In: Droppo, I., Leppard, G., Liss, S., Milligan, T. (Eds.), Flocculation in Natural and Engineered Environmental Systems. CRC Press, Boca Raton, FL, pp. 271-292.

Jackson, G.A., Burd, A.B., 1998. Aggregation in the marine environment. Environmental Science and Technology 32, 2805-2814.

Jackson, G.A., Kiørboe, T., 2008. Maximum phytoplankton concentrations in the sea. Limnology and Oceanography 53 (1), 395-399.

Jackson, G.A., Waite, A.M., Boyd, P.W., 2005. Role of algal aggregation in vertical carbon export during SOIREE and in other low biomass environments. Geophysical Research Letters 32, L13607. doi:10.1029/2005GL023180.

Kanamitsu, M., Ebisuzaki, W., Woollen, J., Yang, S.-K., Hnilo, J.J., Fiorion, M., Potter, J., 2002. NCEP-DOE AMIP-II reanalysis (R-2). Bulletin of the American Meteorological Society 83, 1631-1643.

Karakaş, G., Nowald, N., Blaas, M., Marchesiello, P., Frickenhaus, S., Schlitzer, R., 2006. High-resolution modelling of sediment erosion and particle transport across the NW African shelf. Journal of Geophysical Research 111. doi:10.1029/ 2005JC003296.

Kiørboe, T., Tiselius, P., Mitchell-Innes, B., Hansen, J.L.S., Visser, A.W., Mari, X., 1998. Intensive aggregate formation with low vertical flux during an upwellinginduced diatom bloom. Limnology and Oceanography 43 (1), 104-116.

Kriest, I., 2002. Different parameterizations of marine snow in a 1D-model and their influence on representation of marine snow, nitrogen budget and sedimentation. Deep-Sea Research Part I 49 (12), 2133-2162.

Kriest, I., Evans, G.T., 1999. Representing phytoplankton aggregates in biogeochemical models. Deep-Sea Research Part I 46 (11), 1841-1859.

Kriest, I., Oschlies, A., 2008. On the treatment of particulate organic matter sinking in large-scale models of marine biogeochemical cycles. Biogeosciences 5 (1), 55-72.

Locarnini, R.A., Mishonov, A.V., Antonov, J.I., Boyer, T.P., Garcia, H.E., 2006. World Ocean Atlas 2005. In: Levitus, S. (Ed.), NOAA Atlas NESDIS 61, Temperature, vol 1. US Government Printing Office, Washington DC. 82 pp.

Marchesiello, P., Estrade, P., 2007. Eddy activity and mixing in upwelling systems: a comparative study of Northwest Africa and California regions. International Journal of Earth Sciences. doi:10.1007/s00531-007-0235-6.

Martin, J.H., Knauer, G.A., Karl, D.M., Broenkow, W.W., 1987. VERTEX: carbon cycling in the northeast Pacific. Deep-Sea Research 34 (2), 267-285.

McCave, I.N., 1984. Size spectra and aggregation of suspended particles in the deep ocean. Deep-Sea Research 31 (4A), 329-352.

Moriceau, B., Garvey, M., Ragueneau, O., Passow, U., 2007. Evidence for reduced biogenic silica dissolution rates in diatom aggregates. Marine Ecology Progress Series 333, 129-142.

Nowald, N., Karakas, G., Ratmeyer, V., Fischer, G., Schlitzer, R., Davenport, R.A., Wefer, G., 2006. Distribution and transport processes of marine particulate matter off Cape Blanc (NW-Africa): Results from vertical camera profiles. Ocean Science Discussions 3 (4), 903-938.

Passow, U., 2002. Transparent exopolymer particles (TEP) in aquatic environments. Progress in Oceanography 55, 287-333. 
Penven, P., Marchesiello, P., Debreu, L., Lefèvre, J., 2008. Software tools for pre- and post-processing of oceanic regional simulations. Environmental Modelling and Software 23 (5), 660-662.

Pillskaln, C.H., Lehmann, C., Paduan, J.B., Silver, M.W., 1998. Spatial and temporal dynamics in marine aggregate abundance, sinking rate and flux: Monterey Bay, central California. Deep-Sea Research Part II 45, 1803-1837.

Ploug, H., Grossart, H.P., 2000. Bacterial growth and grazing on diatom aggregates: Respiratory carbon turnover as a function of aggregate size and sinking velocity. Limnology and Oceanography 45 (7), 1467-1475.

Ratmeyer, V., Wefer, G., 1996. A high resolution camera system (parca) for imaging particles in the ocean-system design and results from profiles and a three-month deployment. Journal of Marine Research 54 (3), 589603.
Shchepetkin, A.F., McWilliams, J.C., 2005. The regional oceanic modeling system (ROMS): A split-explicit, free-surface, topography-following-coordinate oceanic model. Ocean Modelling 9 (4), 347-404.

Stemmann, L., Jackson, G.A., Ianson, D., 2004. A vertical model of particle size distributions and fluxes in the midwater column that includes biological and physical processes - part I: model formulation. Deep-Sea Research Part I 51 (7), 865-884.

Stemmann, L., Eloire, D., Sciandra, A., Jackson, G.A., Guidi, L., Picheral, M. Gorsky, G., 2008. Volume distribution for particles between 3.5 to $2000 \mu \mathrm{m}$ in the upper $200 \mathrm{~m}$ region of the South Pacific Gyre. Biogeosciences 5, 299-310. 